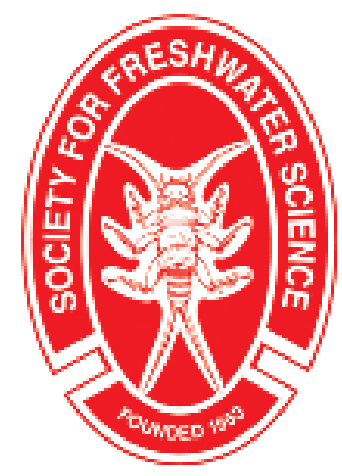

The temperature regimes of dry-season waterholes in tropical northern Australia: potential effects on fish refugia

Author(s): Jim Wallace, Nathan Waltham, Damien Burrows, and David McJannet

Source: Freshwater Science, Vol. 34, No. 2 (June 2015), pp. 663-678

Published by: The University of Chicago Press on behalf of Society for Freshwater Science

Stable URL: http://www.jstor.org/stable/10.1086/681278

Accessed: 28/09/2015 23:02

Your use of the JSTOR archive indicates your acceptance of the Terms \& Conditions of Use, available at

http://www.jstor.org/page/info/about/policies/terms.jsp

JSTOR is a not-for-profit service that helps scholars, researchers, and students discover, use, and build upon a wide range of content in a trusted digital archive. We use information technology and tools to increase productivity and facilitate new forms of scholarship. For more information about JSTOR, please contact support@jstor.org. 


\title{
The temperature regimes of dry-season waterholes in tropical northern Australia: potential effects on fish refugia
}

\author{
Jim Wallace ${ }^{1,3}$, Nathan Waltham ${ }^{1,4}$, Damien Burrows ${ }^{1,5}$, and David McJannet ${ }^{2,6}$ \\ ${ }^{1}$ Centre for Tropical Water and Aquatic Ecosystem Research (TropWATER), James Cook University, Townsville, Queensland 4811 \\ Australia \\ ${ }^{2}$ CSIRO Land and Water, EcoSciences Precinct, Dutton Park, Queensland 4120 Australia
}

\begin{abstract}
The ephemeral rivers in northern Australia break up into a series of waterholes during the long, dry summer season. These in-stream waterholes provide vital habitat for the survival of aquatic biota during this period. We describe how high-time-resolution $(20 \mathrm{~min})$ waterhole temperature measurements made in the Flinders and Gilbert Rivers in tropical northern Australia were used to derive thermal frequency curves that show how often waterhole temperature exceeded any given temperature threshold. During the summer period, temperatures near the surfaces of waterholes were often above that suitable for the optimum growth of some tropical fish $\left(31^{\circ} \mathrm{C}\right)$. At the bottom of waterholes, this exceedance occurred less often, and in turbid waterholes that were stratified, temperatures rarely exceeded this threshold. Temperatures that could be lethal to some fish $\left(34^{\circ} \mathrm{C}\right)$ also were exceeded at the surface of waterholes, but rarely, if ever, at the bottom of waterholes. An energy-balance model was used to estimate daily mean waterhole temperature with good accuracy $( \pm 1 \mathrm{~K})$ at all but the sites where wind speed may have been $>2 \mathrm{~m} / \mathrm{s}$ (assumed in the model). The model also was used to predict the effects of climate change on waterhole temperature and the change in exceedance of thermal thresholds. A $2 \mathrm{~K}$ climate warming raised waterhole temperature by $\sim 1 \mathrm{~K}$. However small this increase might seem, it led to a doubling of the length of time water temperatures were in excess of thresholds around $31^{\circ} \mathrm{C}$.
\end{abstract}

Key words: waterholes, temperature, modeling, thresholds, climate change

Concern is increasing globally about the state of freshwater ecosystems and their continued viability as important refugia and productive areas for fish and other aquatic life (Dudgeon et al. 2006). In an attempt to assess the overall health of freshwater ecosystems, managers typically examine a suite of basic water-quality conditions, which assist in building a picture of the underlying ecological processes, variability, and pressures. Water temperature is arguably the most important water-quality variable because it directly affects habitat suitability for aquatic biota and the rates of many important physical, chemical, and biological processes (Gillooly et al. 2001, Caissie 2006, Acuña et al. 2008, Burrows and Butler 2012). For many aquatic organisms, such as fish, temperature directly controls metabolic rate and, therefore, influences growth, resource allocation for reproduction, and ultimately, population size (Jobling 1995, Caissie 2006). Growth rates and development in fish tend to increase with temperature up to an optimum (defined as their temperature preference $\left[\mathrm{T}_{\text {pref }}\right]$ ) provided that sufficient food is available to sustain growth (McCauley and Casselman 1981, Regier et al. 1990, Eaton et al. 1995, Pusey and Arthington 2003). As temperatures increase beyond this optimum, growth rates decline and fish can become more susceptible to environmental stresses, such as low concentrations of dissolved $\mathrm{O}_{2}$ (Pearson and Pendridge 1992). Ultimately, as water temperature increases further, fish can experience lethal effects (defined as their critical thermal maximum [ $\left.\mathrm{CT}_{\max }\right]$; Lutterschmidt and Hutchinson 1997, Cherry and Cairns 1982, Caissie 2006). Therefore, 2 key water-temperature thresholds are important for fish, $\mathrm{T}_{\text {pref }}$ and $\mathrm{CT}_{\max }$. Thermal regimes and temperature thresholds have been investigated in lotic freshwater ecosystems in many parts of the world (e.g., Canada: Jeong et al. 2013, USA: Fang and Stefan 1999, and Europe: Elliott and Hurley 1997), but the focus has been on permanent (flowing) water bodies. Very few data are available for dry or ephemeral waterholes and river channels (Elliott 2000, Maltchik and Medeiros 2006).

E-mail addresses: ${ }^{3}$ jim.wallace@mail.com; ${ }^{4}$ nathan.waltham@jcu.edu.au; ${ }^{5}$ damien.burrows@jcu.edu.au; ${ }^{6}$ david.mcjannet@csiro.au 
Most rivers in northern Australia are ephemeral, and many break up into a series of waterholes along their axial length in the dry season (Petheram et al. 2009, 2012, Kennard et al. 2010). These in-stream waterholes provide vital habitat for the survival of aquatic biota during this period (Arthington et al. 2010, Bunn and Arthington 2002, Hamilton et al. 2005, Sheldon et al. 2010), which is largely determined by water quality (Waltham et al. 2013). Thus, the aquatic species they support should be well adjusted to the extreme conditions that occur periodically. However, the frequency and degree of these extreme conditions may change in the future under climate change, a situation that was recently assessed in the Flinders and Gilbert catchments in northern Australia by Petheram and Yang (2013a, b). These authors used an ensemble of 15 Global Climate Models (GCMs) with $5-\times 5-\mathrm{km}$ resolution downscaled by using $121 \mathrm{y}$ of historical climate data to simulate the future climate associated with a global mean temperature increase of $2 \mathrm{~K}$ (relative to 1990). The main conclusion from that study was that neither mean annual rainfall nor rainfall intensity would change significantly in the Flinders and Gilbert catchments under the modeled future climate scenario. This lack of change in rainfall implies that river flows should remain similar to historical conditions, so future climate would affect only dry-season waterholes via the effect of $2 \mathrm{~K}$ warmer air temperatures on their water temperature and depth (via increased evaporation). A pressing need exists to characterize the current thermal regime in dry-season waterholes and how it might change under future climate conditions to assess in-stream waterhole function and associated detrimental effects on riverine aquatic species, especially fish.

We described the high-time-resolution (20 min) continuous water-temperature measurements made in a number of in-stream waterholes in the Flinders and Gilbert catchments between September 2012 and May 2013. We examined these data to quantify how waterhole temperature changes as the dry season progresses and how water temperature varies between the surface and bottom layers of the waterholes. We used an energy-balance model to estimate waterhole temperature and compared its predictions to measured waterhole temperatures. To explore how often waterhole temperature approaches and exceeds thresholds that may be detrimental to fish and other aquatic species, we used the 20-min waterhole-temperature data to derive frequency curves that show how often water temperature exceeds any given temperature threshold. We illustrated the exceedance times for 3 preliminary thresholds that encompass a range that includes the temperatures for optimum growth and lethal effects on some tropical fish under current and modeled future climates for both catchments. We used the energy-balance model to simulate the potential effects of climate change on waterhole temperature and the rate of decrease in waterhole depth during the dry season.

\section{METHODS}

Location, weather, and flow conditions

We carried out our study in the Flinders and Gilbert catchments, which drain into the Gulf of Carpentaria in northern Queensland, Australia (Fig. 1). The Flinders has a catchment area of $109,000 \mathrm{~km}^{2},>2 \times$ that of the Gilbert catchment $\left(46,354 \mathrm{~km}^{2}\right)$. Both catchments are predominantly flat, but the Gilbert catchment has some undulations in its mid-to-upper reaches. The maximum elevation in both catchments is $\sim 1050 \mathrm{~m}$. Both catchments have a semi-arid tropical climate with highly seasonal and interannually variable rainfall (Petheram and Yang 2013). In the Flinders catchment, mean annual rainfall varies from $\sim 800 \mathrm{~mm}$ at the coast to $\sim 350 \mathrm{~mm}$ in the south, with a catchment average of $492 \mathrm{~mm}$. The Gilbert catchment is wetter, with a catchment annual average of $775 \mathrm{~mm}$ that varies from $\sim 1050 \mathrm{~mm}$ at the coast to $\sim 650 \mathrm{~mm}$ in the southeastern part of the catchment. A defining characteristic of the climate of both catchments is the high evaporative demand $(\sim 1900 \mathrm{~mm} / \mathrm{y})$ and strongly seasonal rainfall, with $\sim 90 \%$ of rainfall occurring during the wet season (November-April inclusive). Land use in both catchments is dominated by cattle grazing, but several mining operations and small-scale cropping also occur in both catchments (Petheram et al. 2013a, b). Further details of the geography and land use in the 2 catchments were given by Petheram et al. (2013a, b).

The strongly seasonal rainfall produces highly variable river flows in both catchments. Peak flows occur during January to March, and little or no flow exists for several months in the dry season (May-November) (e.g., monthly average flows recorded in the upper Flinders River near Richmond at gauge 915008A; Fig. 2). In-stream waterholes start to form after flow in the river falls to 0 . For practical reasons, zero flow is defined when the gauge records $<1 \mathrm{ML} / \mathrm{d}$ (McJannet et al. 2014). At the location illustrated in Fig. 2, this period averages $\sim 218 \pm 102 \mathrm{~d} / \mathrm{y}$ (Holz et al. 2013).

\section{Temperature measurement and modeling}

We recorded water temperature in 10 waterholes in each catchment with Hobo temperature loggers (Onset Corporation, Bourne, Massachusetts) deployed at 2 depths in each waterhole: 1) $0.2 \mathrm{~m}$ below water surface (surface); and 2) $0.1 \mathrm{~m}$ above the bottom of the waterhole (bottom). We attached the surface logger to the underside of a $0.15-\mathrm{m}$ buoy to shield it from the sun at all times because direct exposure could have produced erroneous results. We positioned loggers in the deepest part of each waterhole. Water depths ranged from 1.5 to $4 \mathrm{~m}$ at the start of the zero-flow period and decreased as the dry season continued. For 13 waterholes where local air-temperature data were not available from existing sources (Bureau of Meteorology), we deployed air temperature loggers (Hobo; Onset Corporation) on the adjacent river bank so that we could compare ambi- 


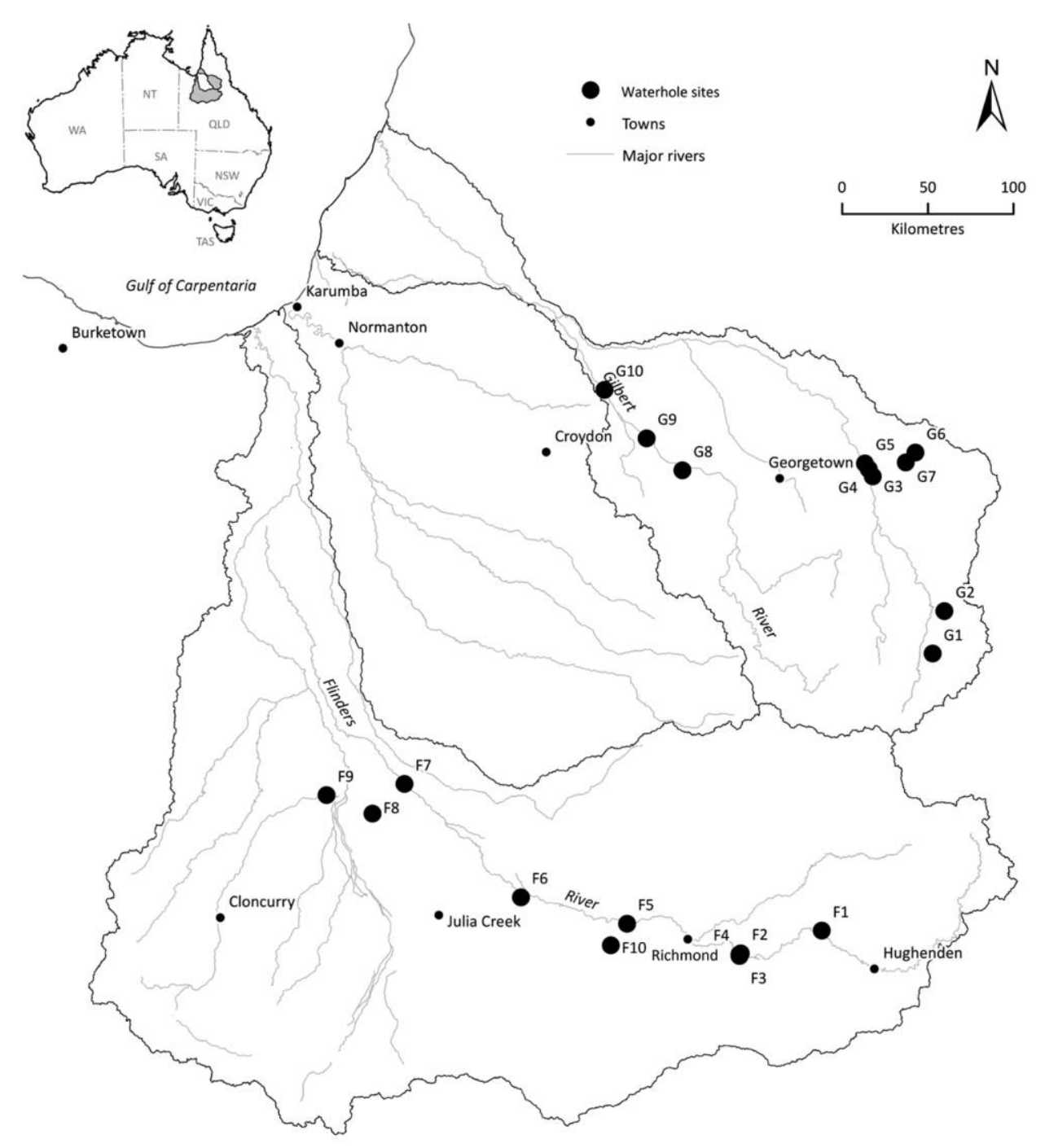

Figure 1. Schematic drawing of the Flinders and Gilbert catchments (Australia) showing the main stream networks and the location of waterholes investigated in the study by Waltham et al. (2013). In our study, only data from waterholes F05, F07, G06, and G10 are presented.

ent air temperature with stream temperature. All loggers (air and water) were programmed to record data every 20 min from 7 September 2012 to 27 May 2013 in the Flinders catchment and from 9 October 2012 to 27 May 2013 in the Gilbert catchment. A full summary of the temperature sensors, loggers, and descriptions of each waterhole were given by Waltham et al. (2013). A complete description of the data from all 20 waterholes is beyond the scope of our paper (Fig. 1), and we present data from 4 waterholes (F05, F07, G06, and G10) that typify the responses seen in a range of waterholes of different size, extent of riparian vegetation, and water clarity.

We estimated waterhole temperature with the energybalance model described by McJannet et al. (2008, 2013). The model was originally developed for estimating daily evaporation from open water bodies of various sizes (ranging from waterholes $\sim 60 \mathrm{~m}$ wide to lakes $\sim 600 \mathrm{~km}^{2}$ in area), but it also can be used to calculate the daily mean waterbody temperature to specify changes in heat storage in a well mixed water column. The main input of energy to the model is solar radiation, and the main losses are via heat conduction to the atmosphere and evaporation.

The daily average water temperature on a given day, $T_{w}$, is calculated with the equilibrium temperature model originally described by De Bruin (1982) as:

$$
T_{w}=T_{e}+\left(T_{w 0}-T_{e}\right) \exp (-1 / \tau)
$$

where $T_{w 0}$ is the water temperature on the previous day and $T_{e}$ is the equilibrium temperature calculated as:

$$
T_{e}=T_{n}+\frac{R_{n}}{4 \sigma\left(T_{n}+273.15\right)^{3}+f\left(u_{2}\right)\left(\Delta_{n}+\gamma\right)}
$$




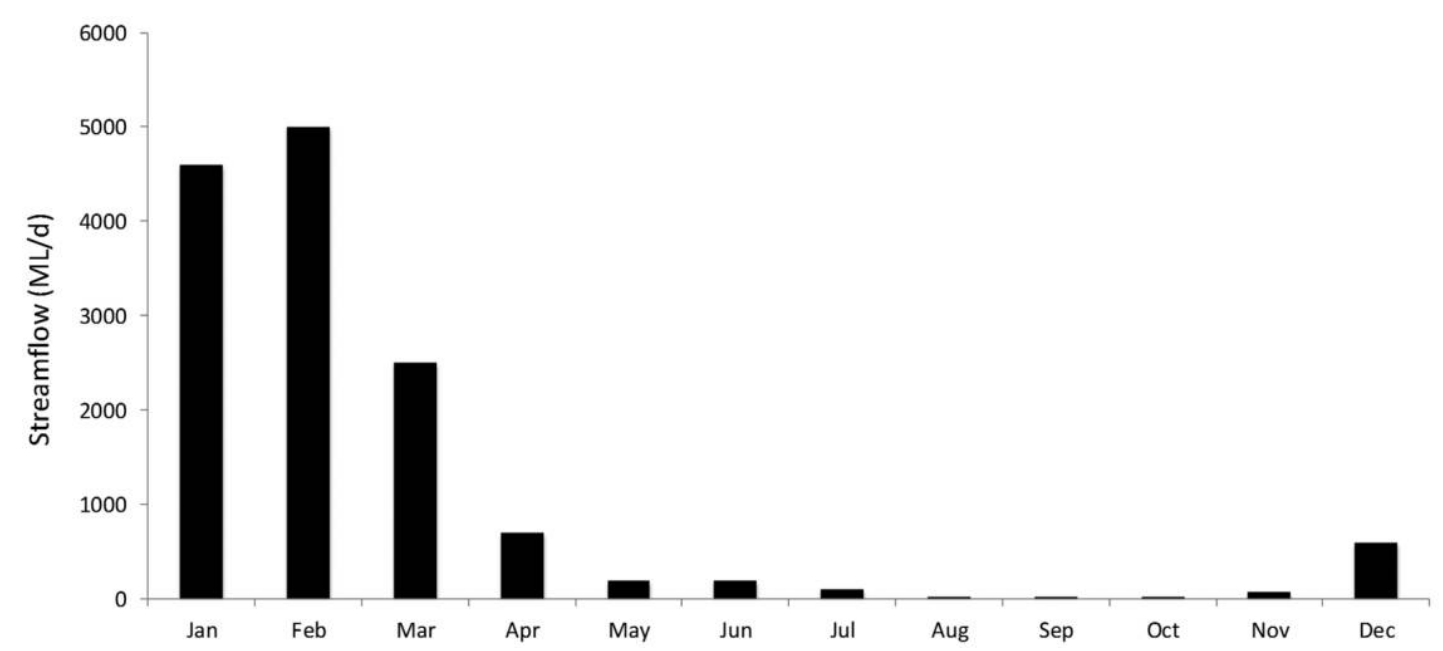

Figure 2. Monthly average flow in the upper Flinders River near Richmond township (gauge 915008A) for the 42-y period from 1971 to 2013. Data from the State of Queensland, Department of Natural Resources and Mines.

where $T_{n}$ is the wet bulb temperature, $R_{n}$ is the net radiation, $\sigma$ is the Stefan-Boltzmann constant, $\Delta$ is the rate of change of saturated vapor pressure with temperature, $\gamma$ is the psychrometric constant, and $f\left(u_{2}\right)$ is the wind function for a water body of area $A$ given by McJannet et al. (2012) as:

$$
f\left(u_{2}\right)=\left(5.78+4.09 u_{2}\right) A^{-0.05}
$$

where $u_{2}$ is the wind speed at $2 \mathrm{~m}$ height. The time constant, $\tau$, in Eq. 1 is calculated as:

$$
\tau=\frac{\rho_{w} c_{w} z}{4 \sigma\left(T_{n}+273.15\right)^{3}+f\left(u_{2}\right)\left(\Delta_{n}+\gamma\right)}
$$

where $\rho_{w}$ is the density of water, $c_{w}$ its specific heat, and $z$ the depth of water.

The evaporation rate, $E$, from the waterhole is given by the Penman-Monteith equation (Monteith 1965) as:

$$
E=\frac{1}{\lambda} \frac{\Delta\left(R_{n}-N\right)+\left(\rho c_{p} D\right) / r_{a}}{\Delta+\gamma}
$$

where $\lambda$ is the latent heat of vaporization of water, $\rho$ is the density of air, $c_{p}$ is the specific heat of air, and $D$ is the saturated vapor pressure deficit of the air. The aerodynamic resistance term, $r_{a}$, is given by McJannet et al. 2013 as:

$$
r_{a}=\frac{\rho c_{p}}{\gamma f\left(u_{2}\right)}
$$

The final term $N$ in Eq. 5 is the change in heat storage in the waterhole calculated as:

$$
N=\rho_{w} c_{w} z\left(T_{w}-T_{w 0}\right)
$$

For in-stream river-channel waterholes, energy also can enter/leave the waterhole if there is flow in the river, but this effect can be ignored here because we modeled only waterhole temperatures in the latter part of the dry season when flow had ceased.

The waterhole temperature model requires daily weather data, which were obtained for each of the waterhole locations from the SILO database (https://www.longpaddock .qld.gov.au/silo/). The SILO database consists of interpolated meteorological variables on a $0.05^{\circ}(\sim 5 \mathrm{~km})$ grid for the whole of Australia (Jeffrey et al. 2001). The particular variables available from SILO used by the waterhole temperature model are air temperature, vapor pressure, solar radiation, and rainfall, and the way these variables are used to calculate all of the terms in the model was described by McJannet et al. (2008). The model also requires daily mean wind speed (to calculate the evaporation rate), and these data are not available in the SILO database. Therefore, we applied a fixed wind speed of $2 \mathrm{~m} / \mathrm{s}$ in the model for each waterhole (see Discussion for the effect of this assumption). Waterhole evaporation rate also depends on waterhole size (area and depth; Eqs 3, 7). Waterhole area affects the 'wind function' (Eq. 3; McJannet et al. 2012) used in calculating evaporation. We used a fixed characteristic area of $10,000 \mathrm{~m}^{2}$, equivalent to a waterhole $100 \times 100 \mathrm{~m}$. Waterhole depth primarily affects heat storage, and the model is run from the beginning of the year so that its depth predictions match depth measurements made in each waterhole during October or November 2012. Sensitivity analysis showed that altering the waterhole area or depth by a factor of 2 changed modeled water temperature by only 0.8 and $0.2 \%$, respectively.

\section{RESULTS}

A typical example of the diurnal variation in waterhole temperature is shown in Fig. 3. Water temperature is generally warmest in mid-afternoon $(\sim 1500 \mathrm{~h})$ and coolest in the early morning $(\sim 0600 \mathrm{~h})$, and its diurnal ampli- 


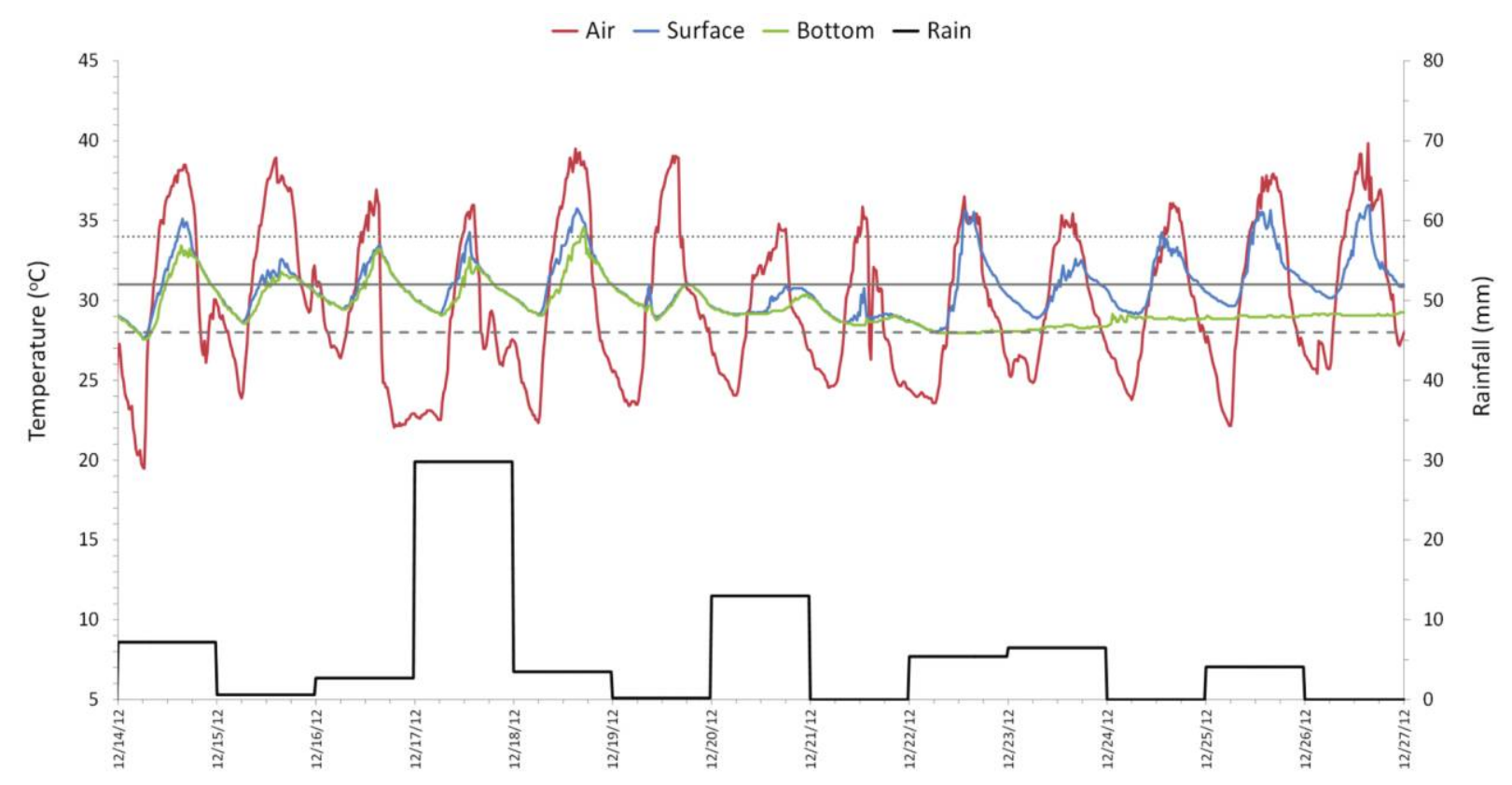

Figure 3. Diurnal oscillations in temperature near the surface and bottom of Flinders catchment waterhole F05 during December 2012. Also shown are concurrent values of air temperature and daily rainfall. The horizontal lines are the 3 temperature thresholds $\left(28,31\right.$, and $\left.34^{\circ} \mathrm{C}\right)$.

tude is much smaller than the diurnal amplitude of air temperature because of the cooling effect of evaporation and the thermal mass of water. In the early part of this time sequence, surface and bottom water temperatures converged overnight, and the surface water layer became a few degrees warmer than the bottom in mid-afternoon. This sequence of waterhole water temperatures is characteristic of well mixed conditions. However, these conditions can change, as shown from the middle of the sequence onward (Fig. 3), when little or no diurnal variation in water temperature occurred at the bottom of the waterhole, whereas temperatures at the surface continued to oscillate in a manner similar to the period immediately before the rainfall (30-70 mm across the catchment) on 17 December 2012. The rainfall was apparently sufficient to generate runoff into the waterhole that contained a large load of fine sediment. The sediment presumably increased the turbidity, thereby reducing light penetration to the bottom of the waterhole where the cooler water became thermally isolated from the surface. This 'thermal stratification' can break down again under windy conditions or if the water turbidity decreases enough to allow solar energy to reach the bottom of the waterhole again. The degree of mixing in a waterhole can affect its suitability as an ecologically viable habitat and the accuracy with which we can model waterhole temperature (see Discussion). The 3 horizontal lines in Fig. 3 represent a range of thermal thresholds for aquatic species (see Discussion). Exceedance of these thresholds clearly depends on depth in the water column and whether it is well mixed or stratified.

\section{Modeling waterhole temperature}

The seasonal trend in waterhole temperature for waterhole F05 in the Flinders River is shown in Fig. 4. The daily mean waterhole temperature for the entire water column (i.e., average of the surface and bottom readings) was $\sim 23^{\circ} \mathrm{C}$ in mid-September and rose steadily to nearly $33^{\circ} \mathrm{C}$ by the end of November. Water temperature generally followed air temperature, but the amplitude was much less variable because the thermal mass of the water damped the higher-frequency changes in air temperature (McJannet et al. 2008). Modeled water temperature followed measured water temperature very closely, especially up to mid-December (Fig. 5). The line fitted to the points up to 14 December 2012 has $r^{2}=0.96$, and in this zero-flow period, the model predicted water temperature to within $1 \mathrm{~K}$ (on average). After this date, the relationship between modeled and measured waterhole temperatures weakened, presumably a response to the occasional flows of water during this time in the catchment (Fig. 3). Flows entered this river reach after 17 December and again on several occasions during the next few months. The grey crosses in Fig. 5 show that the modeled water temperature was less well correlated with the measured water temperature in this period. Modifications to the model to account for flows of known temperature would be needed to improve the model predictions for flowing streams.

The seasonal trend in water temperature recorded in a deeper and more turbid waterhole in the Flinders River, F07 ( $\sim 2.2 \mathrm{~m}$ deep in November/December 2012 cf. $\sim 1.4 \mathrm{~m}$ deep in waterhole F05 at the same time) was 


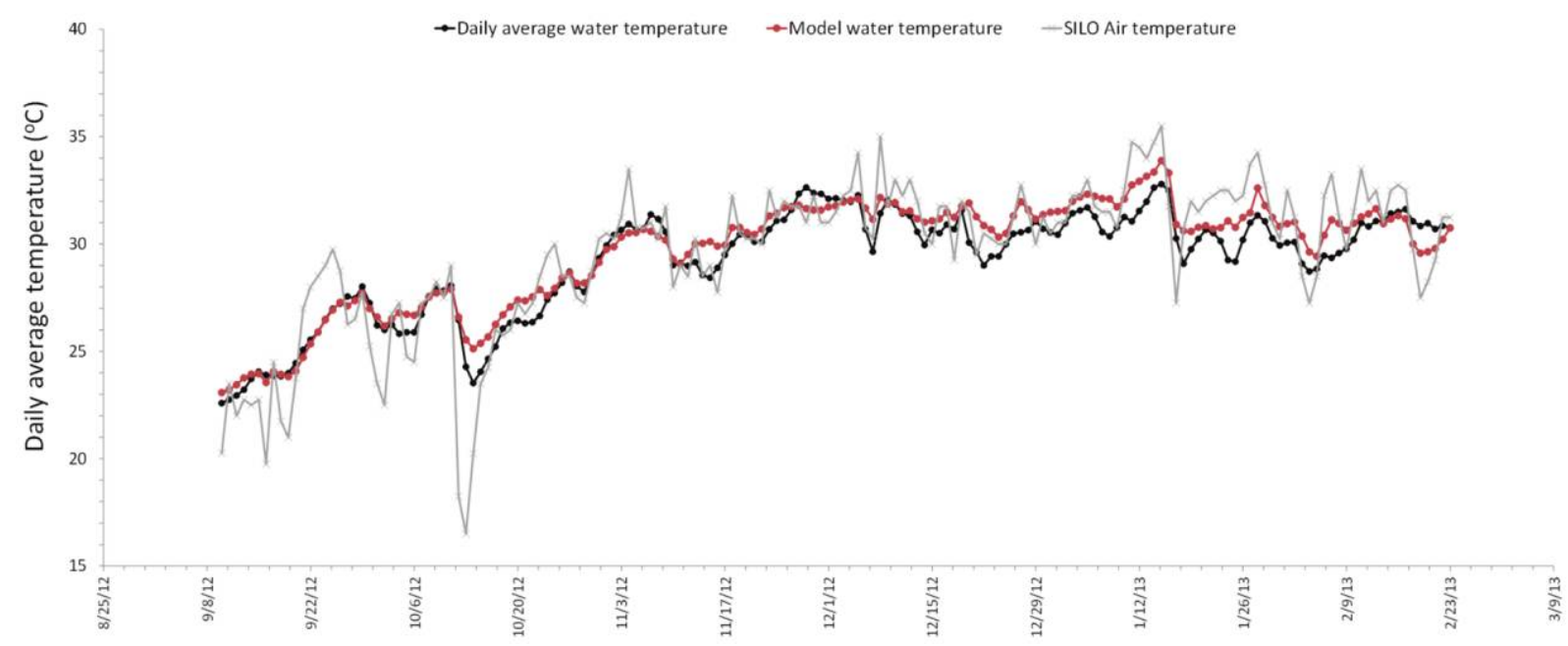

Figure 4. Temporal fluctuations in water temperature in waterhole F05 in the Flinders River near Richmond. Measured daily mean profile water temperature is compared with modeled water temperature, and mean daily SILO air temperature for the location is shown.

similar to that in waterhole F05. Despite its greater depth, waterhole F07 had a daily mean temperature similar to that of waterhole F05 (30.6 and $31.1^{\circ} \mathrm{C}$, respectively) at the hottest time of the year [November/December]; Waltham et al. 2013). The model followed the observed time trend well, but it tended to systematically overestimate the profile mean (average of the surface and bottom readings) water temperature by $\sim 1 \mathrm{~K}$ (Fig. 6A). The model overestimation of waterhole F07 temperature is unlikely to be a result of systematic differences between the SILO air tem- perature (which is a key input to the model) and actual air temperature recorded at the site because these temperatures agreed to within a few tenths of a degree (Waltham et al. 2013). Figure 6A also contains a plot of the measured surface and modeled water temperatures in which the regression falls almost exactly on the $1: 1$ line. This result means that the water temperature model gave a better estimate of the surface water temperature in this deeper or more turbid waterhole than of the profile average or bottom water temperatures.

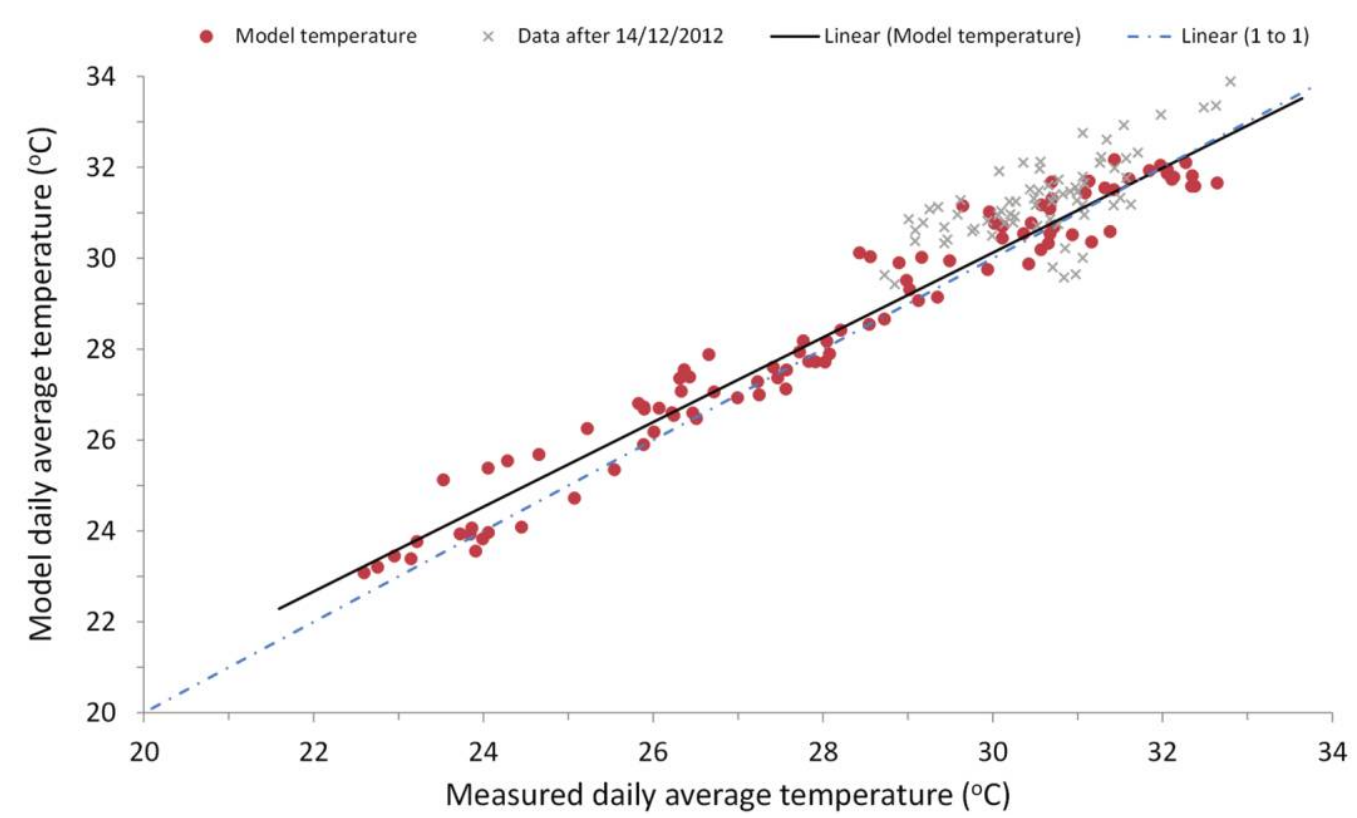

Figure 5. Comparison of modeled and measured water temperature in Flinders River waterhole F05. The regression fitted to the measured mean water temperature recorded during the period of zero flow (9 September-14 December 2012) has the form $y=0.93 x+2.2\left(r^{2}=0.96\right)$. Data points recorded after 14 December are shown as grey crosses. The 1:1 line is also shown. 

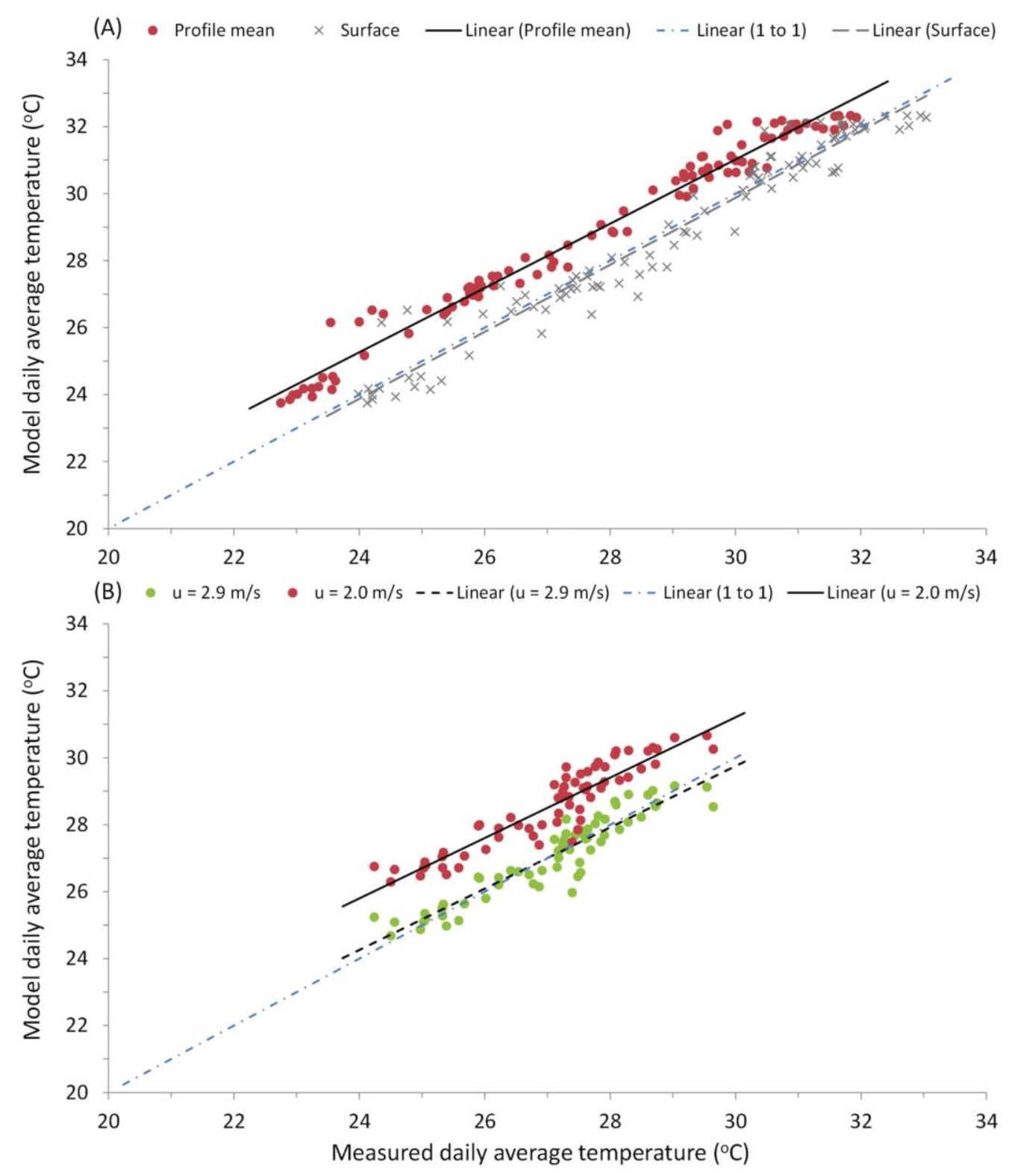

Figure 6. Comparison of modeled and measured water temperature in a thermally stratified waterhole (F07) (A) and a well mixed waterhole (G06) (B). The regression fitted to the modeled profile mean water temperature with a wind speed of $2 \mathrm{~m} / \mathrm{s}$ has the form $\mathrm{y}=$ $0.96 x+2.2\left(r^{2}=0.97\right)$ and $y=0.90 x+4.2\left(r^{2}=0.85\right)$ in panels A and $\mathrm{B}$, respectively. Also shown in panel A is the regression fitted to the measured surface water temperature and, in panel $\mathrm{B}$, the regression fitted to the modeled profile mean water temperatures with a wind speed of $2.9 \mathrm{~m} / \mathrm{s}$. The 1:1 lines are also shown.

In some waterholes, modeled water temperature exceeded the water temperature measured near the surface of the waterhole and the measured mean profile temperature. An example of this is shown for the Gilbert waterhole G06 (Fig. 6B), where modeled water temperatures averaged $1.5 \pm 0.5 \mathrm{~K}$ higher than the mean water temperature and $0.7 \pm 0.5 \mathrm{~K}$ higher than the surface water temperature. Two main possibilities could cause the modeled temperature to be high. First, if the waterhole were shaded, it would not receive the full insolation used as an input to the model. To compensate for this situation, the model offset could be reduced to 0 if shade reduced the insolation by $\sim 20 \%$. However, the waterhole temperature recordings were made near the mid-point between the river banks, and no shade exists across this part of the river waterhole (Waltham et al. 2013). A second possibility is that the wind speed was higher than the fixed $2.0 \mathrm{~m} / \mathrm{s}$ used in the model. The effect of increasing wind speed is shown in Fig. 6B. At a value of $2.9 \mathrm{~m} / \mathrm{s}$ (optimized), no offset exists between modeled and measured mean profile water temperatures. 
Thus, at sites where the wind speed is significantly different from $2.0 \mathrm{~m} / \mathrm{s}$, it may be necessary to obtain local values of wind speed to generate accurate modeled predictions of water temperature.

\section{Waterhole temperature thresholds}

Aquatic species that inhabit waterholes in the Gilbert and Flinders catchments during the summer may experience temperatures that exceed their optimum for growth or even their lethal maximum. A paucity of data exists on exactly what these values are for tropical fish in northern Australia, so we used the 20-min measurements of waterhole temperature to construct frequency plots from which we could calculate exceedance times for a range of temperature thresholds. For example, Fig. 7A, B show plots of the amount of time the temperature at the surface and bottom of waterholes G10 (well mixed) and F07 (stratified) were above a given temperature. The period chosen (14 October 2012-21 January 2013) is the time of year when waterhole temperatures rose from near their annual mean to the
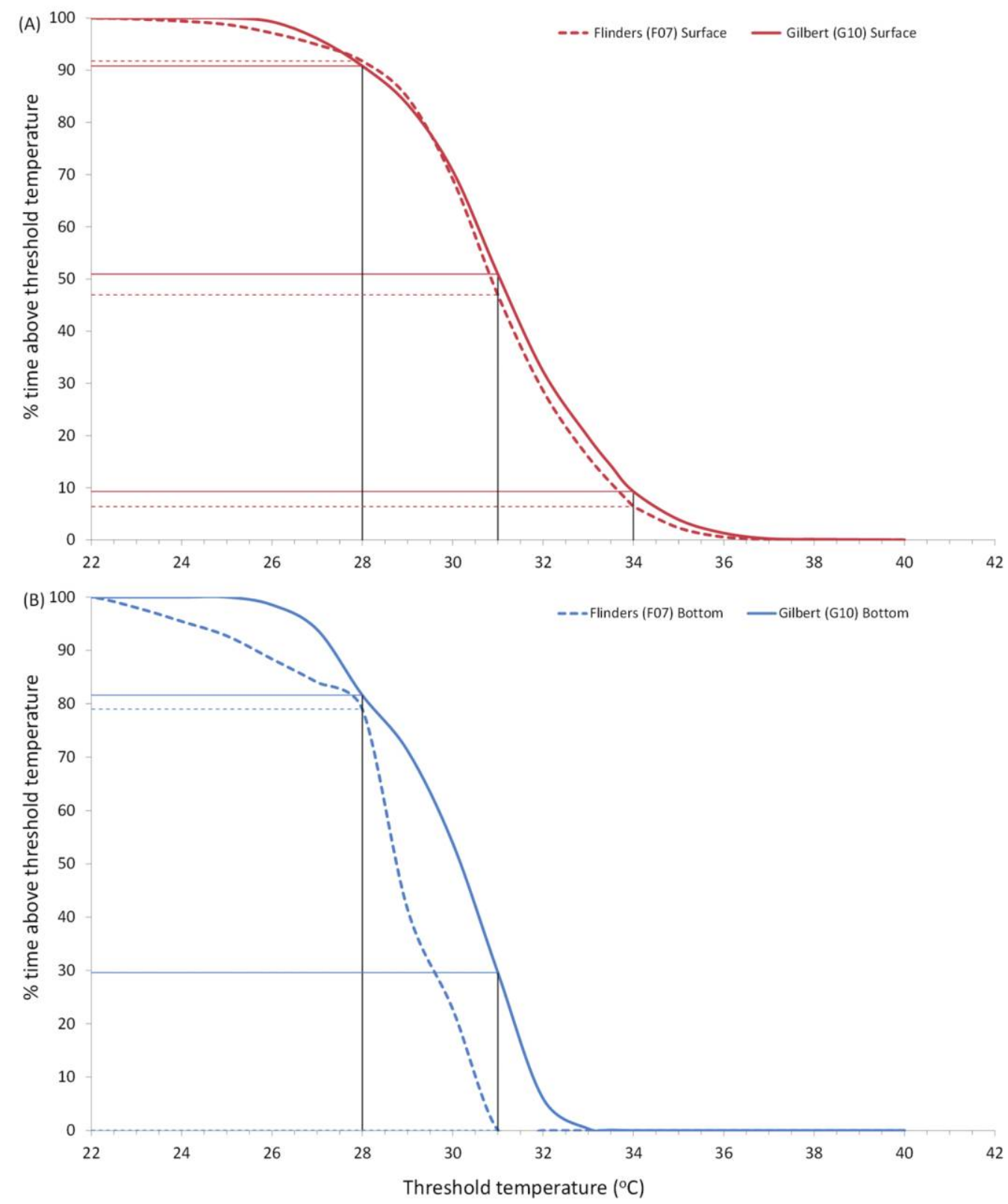

Figure 7. The percentage of time surface (A) and bottom (B) water temperature exceeded a given temperature threshold in Flinders waterhole F07 and Gilbert waterhole G10. The frequency curves were compiled from all 20-min recordings made in the 100-d period from 14 October 2012 to 21 January 2013. 
warmest temperatures recorded during December and January (Fig. 4). Water temperatures declined almost symmetrically in the following 3 mo (Waltham et al. 2013), so the $\%$ times calculated can be taken as representative of the entire summer period (October-March) in this region.

The thermal regimes at the surface of G10 and F07 were quite similar (Fig. 7A). The times above the 3 thresholds shown were 91 and $92 \%\left(\mathrm{~T}_{1}=28^{\circ} \mathrm{C}\right), 51$ and $47 \%$ $\left(\mathrm{T}_{2}=31^{\circ} \mathrm{C}\right)$, and 9.3 and $6.4 \%\left(\mathrm{~T}_{3}=34^{\circ} \mathrm{C}\right)$. In contrast, the temperature regimes at the bottom of these 2 waterholes were much cooler and were quite different in shape (Fig. 7B). The biggest difference occurred at $\mathrm{T}_{2}$, which was exceeded $30 \%$ of the time in water at the bottom of the well mixed waterhole G10, compared to $0 \%$ exceedance of this threshold in the stratified waterhole F07. At the bottom of both waterholes, temperature exceeded $\mathrm{T}_{1} \sim 80 \%$ of the time, but never exceeded $\mathrm{T}_{3}$. Therefore, fish may prefer to remain in the cooler thermal environment at the bottom of these waterholes, but may have to move closer to the surface on occasion if other factors, such as dissolved $\mathrm{O}_{2}$, become limiting. The stratification in the deeper, more turbid waterhole F07 also may provide a thermal regime close to (or below) the preferred optimum for the more sensitive fish for the entire summer period.

\section{Potential effects of climate change}

Concern about the potential impacts of climate change on freshwater ecosystems is widespread. For example, authors of studies in the US and Europe have found that climate-warming increases in waterbody temperature may reduce habitat availability for some fish species and increase it for other species, thereby leading to shifts in species distributions across river networks (Sinokrot et al. 1995, Eaton and Scheller 1996, Buisson et al. 2008, Jeong et al. 2013). Potential future changes in the climate in the Flinders and Gilbert catchments could affect the thermal environment of dry-season waterholes and their suitability as freshwater refugia. Future climate associated with a global mean temperature increase of $2 \mathrm{~K}$ (i.e., historic climate +2 degrees Kelvin) has recently been assessed by Petheram and Yang (2013). We simulated how dry-season waterhole temperature and depth might change under $2 \mathrm{~K}$ warmer air temperatures, assuming that the onset and duration of the period of zero flow did not change. This assumption is consistent with the lack of change in rainfall across the Flinders and Gilbert catchments found by Petheram and Yang (2013). This lack of change implies that river flows should remain as they have been historically.

Zero-flow (or cessation of flow) conditions in the Flinders and Gilbert catchments were defined as when gauged flow is $<1 \mathrm{ML} / \mathrm{d}$ in a companion study of dryseason waterholes by McJannet et al. (2014). They found that the mean duration of zero flow in the mid-Flinders River was 225 d, substantially longer than in the Gilbert River (160 d). We chose the longer zero-flow period in the Flinders River to illustrate the potential effect of climate change on waterhole temperature. Flow in the Flinders catchment typically approaches 0 by the end of April (Lerat et al. 2013), so we started zero flow on 1 May and ended it $225 \mathrm{~d}$ later on 11 December.

The effect of a $2 \mathrm{~K}$ warming on waterhole depth, temperature, and evaporation during the zero-flow period in the mid-Flinders is shown in Fig. 8A-C. Under the current climate, waterhole depth decreased steadily from $2 \mathrm{~m}$ on 1 May (set in the model) to $0.85 \mathrm{~m}$ on 11 December. Under the climate-warming scenario, waterhole depth declined slightly faster, but was only $90 \mathrm{~mm}$ shallower by the end of the simulation period (Fig. 8A). This result was a direct consequence of the higher evaporation rate under climate warming, which increased by $\sim 0.4 \mathrm{~mm} / \mathrm{d}$ (Fig. $8 \mathrm{C}$ ). Climate warming had a relatively small effect on the decline in waterhole depth, and, therefore would not have a major effect on deeper waterholes. Simulated waterhole temperature increased from a minimum of $15^{\circ} \mathrm{C}$ in July to a maximum of $32^{\circ} \mathrm{C}$ in December (Fig. $8 \mathrm{~B}$ ). Under the $2 \mathrm{~K}$ warmer future climate, water temperatures were elevated, but only by $1.07 \pm 0.08 \mathrm{~K}$ on average. This 'damping' of the air warming was caused by the increased rate of evaporation under the warmer climate and demonstrates how water bodies provide a buffering effect on climate change.

We illustrated the impact of climate change on the frequency with which waterhole temperature exceeds any given value for waterhole $\mathrm{G} 10$ by adding $1.07 \mathrm{~K}$ to the current temperature recordings (Fig. 9A, B). This illustration showed substantial increases in the percentage of time where the water in G10 exceeded the temperature thresholds. For example, exceedance of $\mathrm{T}_{2}$ in surface water increased from 51 to $73 \%$ and of $\mathrm{T}_{3}$ from 9 to $20 \%$. Bottom water temperature exceedance of $\mathrm{T}_{2}$ increased from 30 to $56 \%$, but exceedance of $\mathrm{T}_{3}$ ( 0 under both current and future climates) did not change. Hence, climate change that increased waterhole temperature by just over $1 \mathrm{~K}$ caused substantial increases in the amount of time the water temperature exceeded critical thresholds. This result is a consequence of the steep shape of the frequency curves over most of their range. Substantial increases in threshold exceedance would occur under a future warmer climate for any critical aquatic threshold in the range $\sim 28$ to $35^{\circ} \mathrm{C}$ (Fig. 10). The largest increase in threshold exceedance occurred between 31 and $32^{\circ} \mathrm{C}$, and the effect of climate warming on thresholds $<26^{\circ} \mathrm{C}$ or $>38^{\circ} \mathrm{C}$ were minimal.

Table 1 provides a summary of the potential effect of climate change on the frequency and duration of events where water temperature exceeded $\mathrm{T}_{2}$ and $\mathrm{T}_{3}$, in a clear waterhole (G10) and a turbid waterhole (F07). Near the surface of the waterholes, temperatures were similar (Fig. 7A). $\mathrm{T}_{2}$ was exceeded less often under the future climate because some events that occurred during the current climate merged under the future climate. In consequence, the aver- 
age duration of $\mathrm{T}_{2}$ exceedance approximately doubled under the future climate, and the maximum event duration rose from $\sim 7$ to $23 \mathrm{~d}$ in waterhole $\mathrm{G} 10$ and from $\sim 2$ to $14 \mathrm{~d}$ in waterhole F07. Water temperatures at the bottom of the 2 waterholes were cooler and, therefore, exceeded $\mathrm{T}_{2}$ on fewer occasions and for shorter durations than at the surface. However, climate change had a marked effect on the length of time that bottom water exceeded $\mathrm{T}_{2}$.

$\mathrm{T}_{3}$ was exceeded between 113 and 151 times for an average of $\sim 2.5$ to $4 \mathrm{~h}$ at the surface in both waterholes, but only 5 times for $\sim 1 \mathrm{~h}$ at the bottom of G10 and never in F07 (Table 1). Climate change doubled the duration of these events in G10, but had no effect in F07. Therefore, a marked difference existed between the thermal regimes at the bottom of waterholes G10 and F07, with the latter rarely exceeding the higher temperature thresholds currently or under the future climate scenario.

\section{DISCUSSION}

\section{Temperature model}

The water-temperature model we used predicted instream waterhole temperatures to within $1 \mathrm{~K}$ in well mixed, nonflowing waterholes. When the waterhole was stratified, modeled water temperatures were correlated more closely with the surface than bottom water temperature and could be 1 to $2 \mathrm{~K}$ above the profile mean water temperature. Therefore, the model was good at predicting the water temperature of the well mixed (surface) layer above the stratification level. In waterholes where temperature change with depth was highly nonlinear (as in some deep waterholes and thermally stratified waterholes), the arithmetic average of 2 measurements made near the surface and near the bottom may not be a good representation of the true water profile average temperature. If the water profile consists of a relatively thick layer of warmer water overlying a thinner
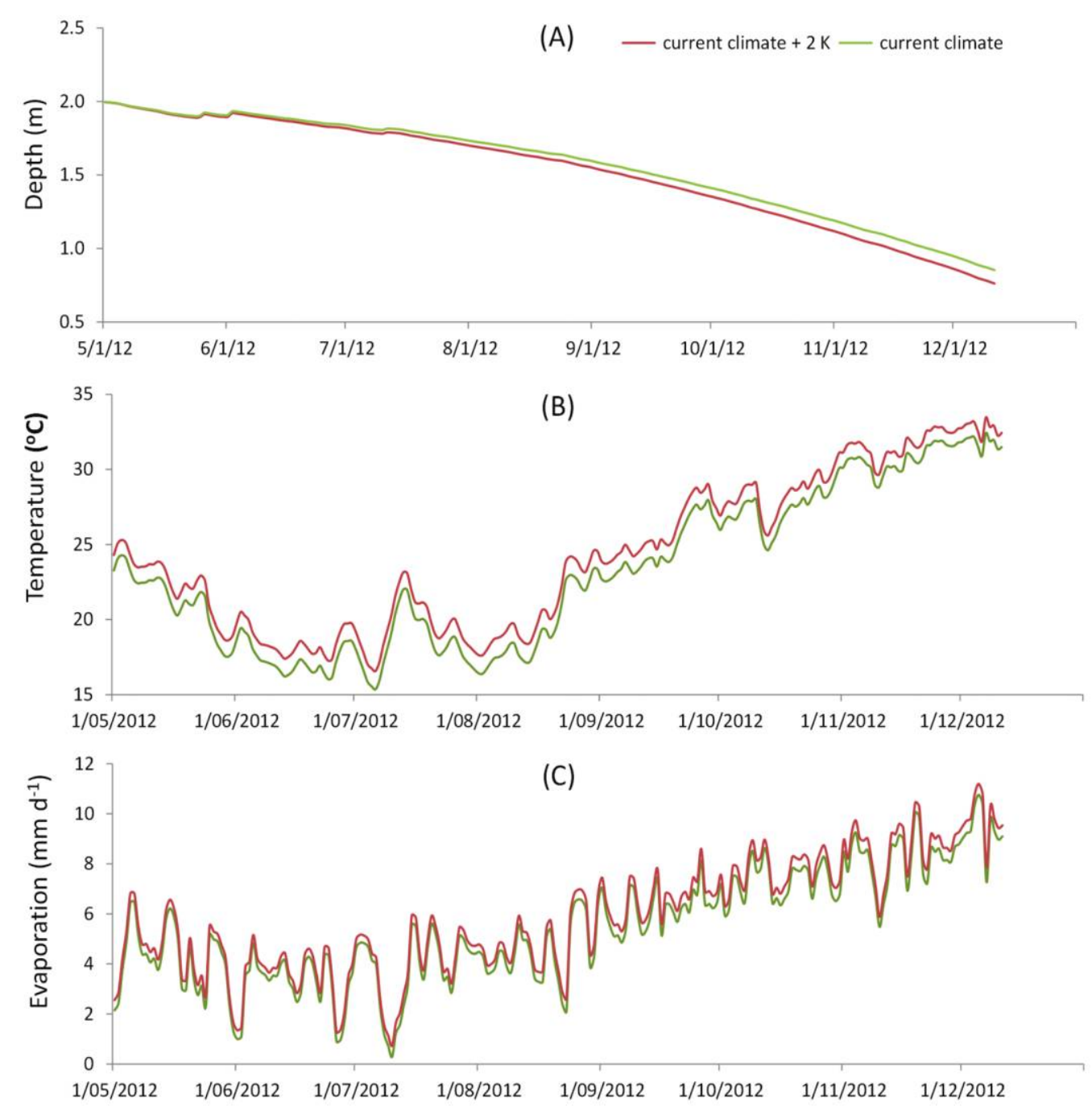

Figure 8. A comparison of the seasonal trend in waterhole depth (A), temperature (B), and evaporation rate (C) for a 2-m waterhole in the mid-Flinders River under current climate and a future climate that is $2 \mathrm{~K}$ warmer. 

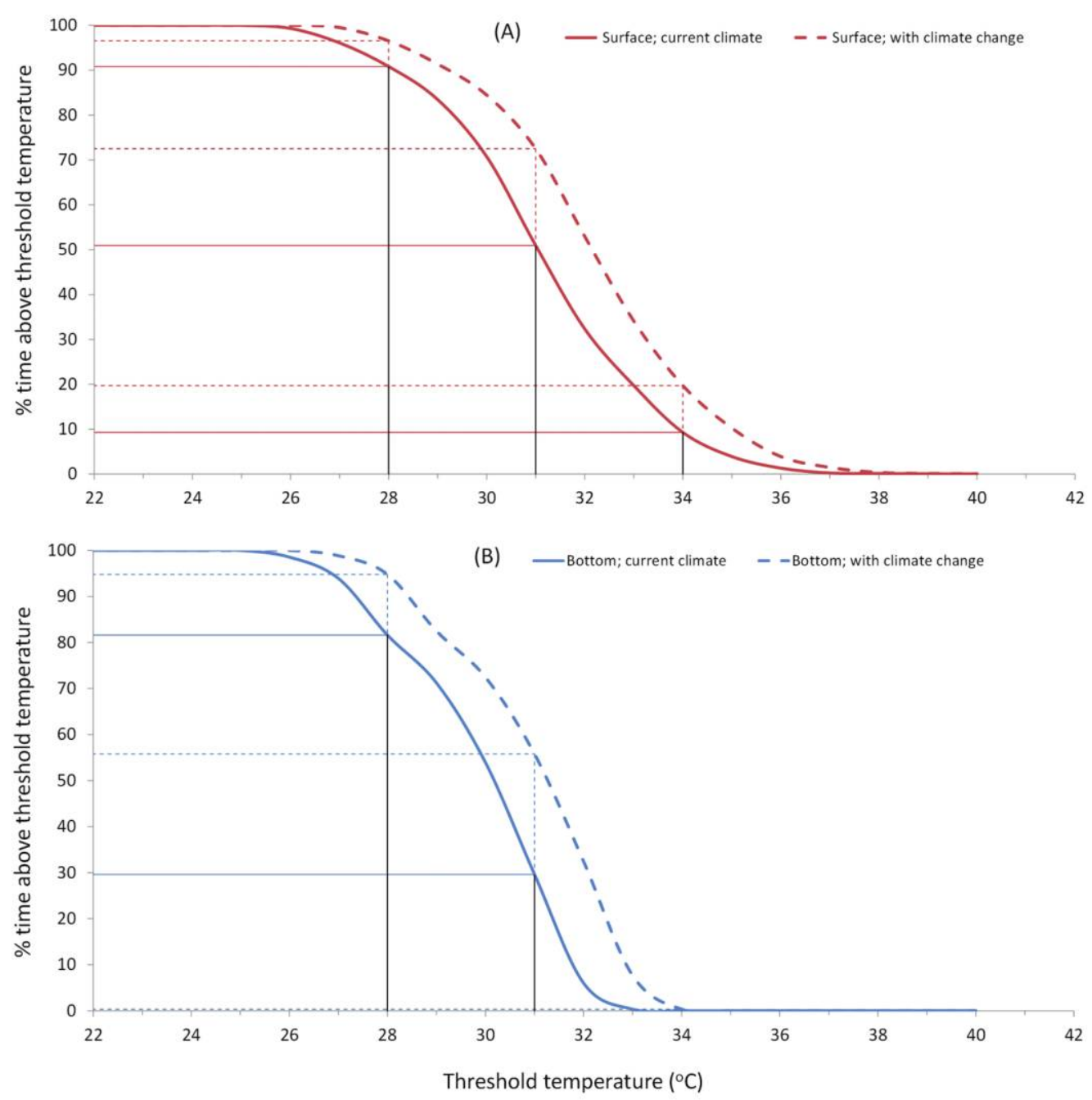

Figure 9. The effect of climate change on the percentage of time surface (A) and bottom (B) water temperature exceed a given temperature threshold in waterhole G10. For comparison, the surface and bottom frequency curves for the current climate (as in Fig. 7) are shown.

layer of cooler water, then the average of the surface and bottom readings will tend to be an underestimate of the true profile mean water temperature. Temperature readings at $>2$ depths may be required if the true profile mean water temperature is needed. In stratified waterholes, the disagreement between the model and the profile average water temperature also may be partly a consequence of this error in calculating the profile average.

Model overestimation of waterbody temperature by $\sim 1.5 \mathrm{~K}$ also was reported by McJannet et al. (2008) for a billabong and river weir in the Murray-Darling basin of similar characteristic dimensions to the waterholes reported here. McJannet et al. (2008) attributed the model overestimation of water temperature to underestimation of wind speed associated with changes in wind direction; i.e., winds were stronger when they were parallel to the length of the waterhole and weaker when they were per- pendicular to the length of the waterhole and slowed by the surrounding riparian vegetation. We also demonstrated that a $\sim 50 \%$ increase in wind speed can reduce water temperature by 1 to $2 \mathrm{~K}$, but locally measured wind speed and direction measurements would be required to improve the model to account for this effect.

The above factors suggest that the absolute accuracy of the water-temperature model when using readily available SILO weather data is between 1 and $2 \mathrm{~K}$. However, the prediction of a change in water temperature consequent to $2 \mathrm{~K}$ climate warming is more accurate $(1.07 \pm$ $0.08 \mathrm{~K})$, assuming that the only factor that changes in the future is the air temperature. Any future changes in other factors, such as cloudiness and wind speed, also would affect the water-temperature change. For example, if the future climate were $10 \%$ more cloudy, then water temperatures would be $\sim 0.5 \mathrm{~K}$ cooler. Moreover, water tem- 


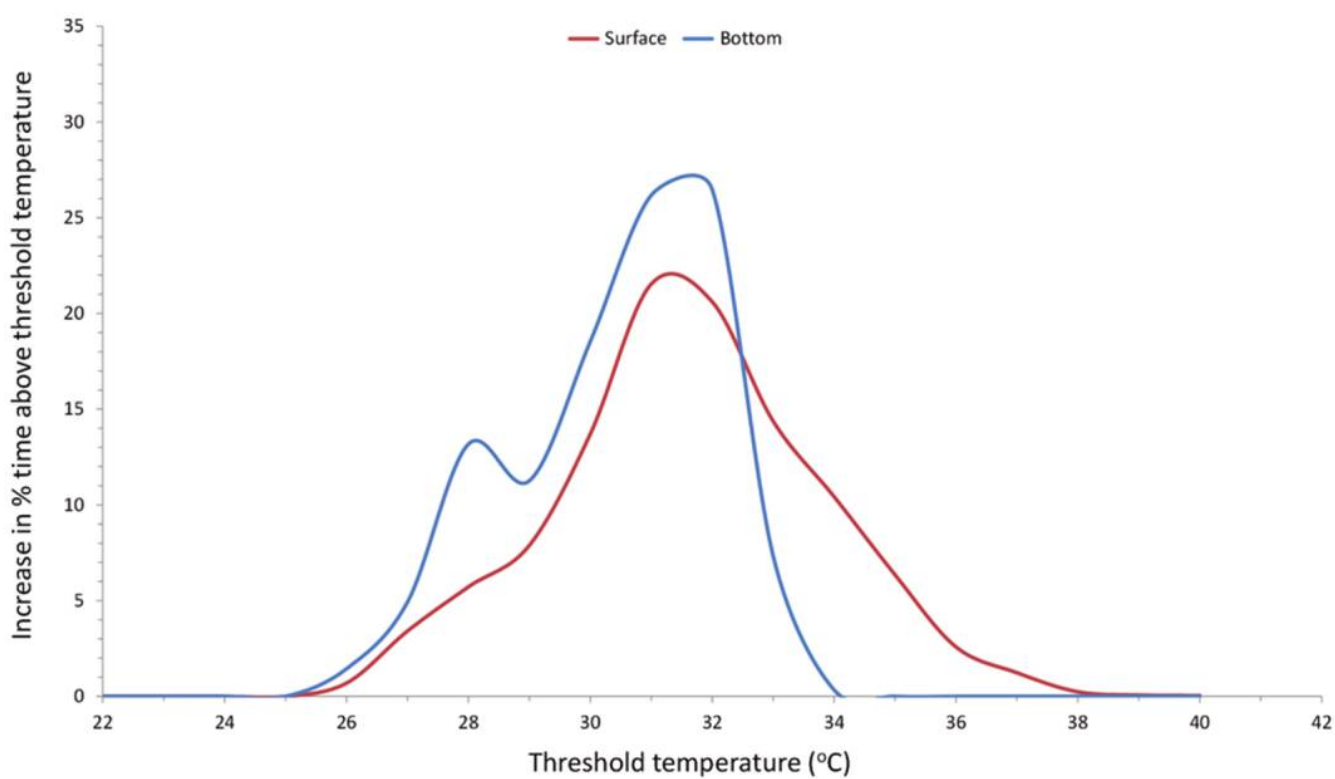

Figure 10. Increase in the percentages of time surface and bottom water temperatures exceed a given temperature threshold in waterhole G10 under a scenario of climate warming.

perature is sensitive to wind speed, but future climate models rarely include simulations of how wind speed might change.

\section{Temperature thresholds}

Most of the evidence for water temperature thresholds for tropical Australian fish comes from studies in which water temperature was recorded incidentally with the presence of various fish species (e.g., Pusey et al. 2004). These data have their drawbacks, in that they are spot measurements made at various times of the day near the surface at the location where the fish were observed. Nevertheless, they can be used to give guidelines to what thermal thresholds might exist for tropical species. For example, Pusey et al. (2004) reported that in the
Burdekin River the commonly occurring Bony Bream (Nematalosa erebi) usually were not found in waters $>31^{\circ} \mathrm{C}$ and, although they can tolerate higher temperatures, they clearly prefer habitats $<31^{\circ} \mathrm{C}$, given the geographical distribution of this species across most inland waters of Australia (Pusey et al. 2004). Similarly, Casselman (2002) reported preferred water temperatures from 27 to $31^{\circ} \mathrm{C}$ for warmwater fish in Lake Ontario, North America, in a temperate climate that is substantially cooler than the northern Australian tropics. Eaton et al. (1995) also found that the optimum thermal range for warmwater fish in North America was 24 to $30^{\circ} \mathrm{C}$. Such data are important and necessary to assist managers and ecologists more broadly with river ecosystem protection and conservation (Dudgeon et al. 2006).

Table 1 . The effect of climate change on the frequency and duration of time that surface and bottom water temperature exceed the 2 temperature thresholds, $\mathrm{T}_{2}=31^{\circ} \mathrm{C}$ and $\mathrm{T}_{3}=34^{\circ} \mathrm{C}$ in waterholes $\mathrm{G} 10$ and F07.

\begin{tabular}{|c|c|c|c|c|c|c|c|c|}
\hline \multirow[b]{2}{*}{ Waterhole } & \multirow[b]{2}{*}{$\begin{array}{l}\text { Threshold } \\
\text { temperature }\end{array}$} & \multirow[b]{2}{*}{ Climate } & \multicolumn{3}{|c|}{ Surface } & \multicolumn{3}{|c|}{ Bottom } \\
\hline & & & $\begin{array}{c}\text { No. } \\
\text { events }\end{array}$ & $\begin{array}{c}\text { Average } \\
\text { duration }(\mathrm{h})\end{array}$ & $\begin{array}{c}\text { Maximum } \\
\text { duration (h) }\end{array}$ & $\begin{array}{c}\text { No. } \\
\text { events }\end{array}$ & $\begin{array}{c}\text { Average } \\
\text { duration (h) }\end{array}$ & $\begin{array}{c}\text { Maximum } \\
\text { duration (h) }\end{array}$ \\
\hline \multirow[t]{4}{*}{ G10 } & 31 & Current & 155 & 14 & 162 & 139 & 9.4 & 84 \\
\hline & & Future & 110 & 29 & 547 & 102 & 24 & 215 \\
\hline & 34 & Current & 151 & 4.1 & 14 & 5 & 0.8 & 1.3 \\
\hline & & Future & 153 & 7.5 & 19 & 42 & 1.9 & 14 \\
\hline \multirow[t]{4}{*}{ F07 } & 31 & Current & 193 & 11 & 42 & 4 & 0.8 & 1.3 \\
\hline & & Future & 130 & 24 & 332 & 27 & 39 & 216 \\
\hline & 34 & Current & 113 & 2.5 & 9 & 0 & 0 & 0 \\
\hline & & Future & 179 & 4.2 & 13 & 0 & 0 & 0 \\
\hline
\end{tabular}


Unfortunately, no systematic data on chronic lethal temperature exposure exist for most tropical fish. The best data that are currently available are the acute thermal tolerance tests done by Burrows and Butler (2012). These authors exposed 7 fish and 4 crustacean species to water temperatures from 28 to $42^{\circ} \mathrm{C}$ to estimate $\mathrm{CT}_{\max }$. This process involved raising the temperature of the test water over a defined period ( $15 \mathrm{~min}-2.5 \mathrm{~h}$ ) and recording the temperature at which the fish lost their ability to stay upright (Burrows and Butler 2012). In that study, $\mathrm{CT}_{\max }$ values ranged from $33.5^{\circ} \mathrm{C}$ for Fly Speckled Hardyhead (Craterocephalus stercusmuscarum) to $41.8^{\circ} \mathrm{C}$ for Barramundi (Lates calcarifer). The lower end of this range of temperatures is similar to the upper thermal limits for warmwater fish in North America, reported by Eaton et al. (1995) to be 33 to $36^{\circ} \mathrm{C}$.

The above studies imply that tropical fish in the Flinders and Gilbert waterholes may have preferred temperatures between 28 and $31^{\circ} \mathrm{C}$ and $\mathrm{CT}_{\max }$ in the range of 34 to $42^{\circ} \mathrm{C}$. Our temperature-threshold analysis shows that $\mathrm{T}_{\text {pref }}$ may be exceeded frequently during summer, especially in clear, well mixed waterholes where radiation penetration raises water temperatures throughout the depth profile. Moreover, our models showed large effects of climate warming on the duration of exceedance of temperatures between 28 and $35^{\circ} \mathrm{C}$. Fish with $\mathrm{T}_{\text {pref }}$ in this range may, therefore, be at risk in the future. Furthermore, the more vulnerable species will be those whose $\mathrm{CT}_{\max }$ also fall within this range.

Exceedance of $\mathrm{CT}_{\max }$ also appears to be significant for some fish (e.g., Fly Speckled Hardyhead), but more robust species, such as Barramundi, can survive even the warmest waterhole temperatures recorded in our study (Newton et al. 2010). This ability is important given the high recreational and commercial importance of Barramundi in Australia (ABARES 2010). More turbid waterholes that stratify provide a cooler thermal environment near their bottoms, which may be more desirable for some fish, but their ability to remain near the bottom may be limited by other factors, such as the level of dissolved $\mathrm{O}_{2}$. Furthermore, fish would use important energy reserves while searching for suitable thermal refugia and could expose themselves to low dissolved $\mathrm{O}_{2}$ conditions (Waltham et al. 2013).

Climate warming of $2 \mathrm{~K}$ increased waterhole temperatures only by $1.07 \mathrm{~K}$ ( $54 \%$ of the air temperature rise), and similar damping of the air temperature rise has been reported in other studies of climate effects on river water temperature. For example, in a global analysis, van Vliet et al. (2011) used air temperature increases between 2 and $6 \mathrm{~K}$ and found that river water temperature increases were $\sim 65 \%$ of the air temperature rise. In Canada, Jeong et al. (2013) used a range of air temperature increases (2-4 K) and found that river-water-temperature increases were $\sim 59 \%$ of the air temperature increases.
The temperature regime in the Flinders and Gilbert waterholes also could have indirect effects on fish via its effect on aquatic invertebrates that provide an important basal part of the food chain. For example, Stewart et al. (2013) reported upper thermal tolerances (equivalent to $\mathrm{CT}_{\max }$ ) of a range of key taxonomic groups of stream invertebrates derived from a global literature review and laboratory experiments on southwestern Australian species. Several taxonomic groups of flies and freshwater shrimps (Ephemeroptera, Diptera, and Amphipoda) have $\mathrm{CT}_{\max }$ values between 22 and $27^{\circ} \mathrm{C}$, which would be exceeded most of the time during the summer in the region we studied. However, several important groups of worms, snails, and crustaceans (Oligochaeta, Planaria, Mollusca, and Decapoda) have thermal tolerances in the range 27 to $32^{\circ} \mathrm{C}$, close to the temperature where climate change has the greatest impact (Fig. 10). Thus, these groups may be more vulnerable in the future. Some species of dragonflies and beetles (Odonata and Coleoptera) have high thermal tolerance $\left(42-43^{\circ} \mathrm{C}\right)$, and would not experience much change in exceedance of $\mathrm{CT}_{\max }$ under a warmer climate. Differences in the thermal tolerances of different freshwater invertebrates imply that climate change may alter the structure of invertebrate assemblages, with as yet, unknown consequences for the fish that depend on them as food sources. This issue is particularly relevant in freshwater river systems that have extended low- or zero-flow periods, such as the waterholes examined here.

\section{Conclusions}

High-time-resolution temperature measurements revealed important aspects of the thermal regime and, therefore, aquatic habitat suitability, operating in waterholes in dry-tropical river systems of northern Australia. Diurnal temperature fluctuations near the surface and bottom of waterholes can be used to define when they become stratified and when they respond to waterhole clarity and, potentially, groundwater influence. These data can be used to construct thermal-frequency curves, which provide an estimate of how long the waterhole temperature is above critical thresholds, such as the optimal and lethal thresholds for aquatic species, including fish. In the tropical, highly seasonal catchments we examined, water near the surface of waterholes often exceeded optimal and even potentially lethal (on fewer occasions) temperatures. Water at the bottom of shallow or clear waterholes also exceeded optimal temperatures, but on fewer occasions and for shorter durations than at the surface. In contrast, deep or turbid waterholes could sustain bottom water temperatures below both the optimal and lethal thresholds throughout the entire summer and, therefore, were more thermally suited for fish, especially if they remained close to the bottom of the waterhole. Whether fish can do this is influenced by other factors, such as food supply and dissolved $\mathrm{O}_{2}$ levels, either of which may still require the fish to spend at least 
some time near the surface of the waterhole (Waltham et al. 2013).

Daily mean water temperatures can be modeled using readily available weather data with reasonable accuracy in waterholes that are well mixed. When stratification occurs (because of high turbidity, deep water, or low wind speed), the model overestimates the profile mean water temperature and is closer to the surface water temperature. The model also overestimates water temperature when the wind speed is significantly higher than the fixed $2 \mathrm{~m} / \mathrm{s}$ used in our study, and locally measured wind speeds should be used if they are available.

The model can be used to simulate how waterhole temperature increases with climate change. For a $2 \mathrm{~K}$ warmer air temperature, waterhole temperature increased by just over $1 \mathrm{~K}$. The damping of the air temperature increase is caused by the additional energy loss associated with the increase in evaporation in the warmer climate. Similar damping has been observed in other studies, so in the absence of specific climate-effect modeling, river water temperatures can be expected to increase by $\sim 60 \%$ of the future climate rise in air temperature.

Waterhole temperature increased by just over $1 \mathrm{~K}$ under a warmer climate in our study, but this small increase had a strong effect on the amount of time water temperatures exceeded optimal and potentially lethal thresholds for fish. The average duration of exceedance doubled under the warmer climate, and the maximum exceedance duration could increase by an order of magnitude. Our conclusions are based on scant, preliminary estimates of optimal and lethal thresholds for tropical fish, but substantial increases in threshold exceedance will occur under a future warmer climate for any critical aquatic thresholds in the range $\sim 28$ to $35^{\circ} \mathrm{C}$. A pressing need clearly exists to establish both chronic and acute thermal tolerance thresholds for a range of aquatic species in tropical rivers that are at most risk of climate-change effects.

\section{ACKNOWLEDGEMENTS}

Major funding for the Flinders and Gilbert Agricultural Resource Assessment was provided by the Office of Northern Australia and the Australian Government's Northern Australia Sustainable Futures program. CSIRO co-invested through its Water for a Healthy Country and Sustainable Agriculture flagships. We thank T. Power and A. Wood for field assistance. We also acknowledge the State of Queensland Department of Natural Resources and Mines as the source of the river flow data in Fig. 2.

\section{LITERATURE CITED}

ABARES (Australian Bureau of Agricultural and Resources Economics Sciences). 2010. Australian fisheries status. Australian Government, Canberra, Australia. (Available from: http:// www.agriculture.gov.au/fisheries) $\rightarrow$ Acuña, V., A. Wolf, U. Uehlinger, and K. Tockner. 2008. Temperature dependence of stream benthic respiration in an $\mathrm{Al}$ pine river network under global warming. Freshwater Biology 53:2076-2088.

$\rightarrow$ Arthington, A. H., R. J. Naiman, M. E. McClain, and C. Nilsson. 2010. Preserving the biodiversity and ecological services of rivers: new challenges and research opportunities. Freshwater Biology 55:1-16.

$\rightarrow$ Buisson, L., W. Thuiller, S. Lek, P. Lim, and G. Grenouillet. 2008. Climate change hastens the turnover of stream fish assemblages. Global Change Biology 14:2232-2248.

$\rightarrow$ Bunn, S. E., and A. H. Arthington. 2002. Basic principles and ecological consequences of altered flow regimes for aquatic biodiversity. Environmental Management 30:492-507.

Burrows, D., and B. Butler. 2012. Preliminary studies of temperature regimes and temperature tolerance of aquatic fauna in freshwater habitats of northern Australia. Report 12/01 (February 2012). Centre for Tropical Water and Aquatic Ecosystem Research, James Cook University, Townsville, Australia. (Available from: https://research.jcu.edu.au/tropwater/publica tions/technical-reports)

$\rightarrow$ Caissie, D. 2006. The thermal regime of rivers: a review. Freshwater Biology 51:1389-1406.

Casselman, J. M. 2002. Effects of temperature, global extremes and climate change on year-class production of warmwater, coolwater and coldwater fishes in the Great Lakes Basin. American Fisheries Society Symposium 32:39-60.

$\rightarrow$ Cherry, D. S., and J. Cairns. 1982. Biological monitoring, part V: preference and avoidance studies. Water Research 16:263301.

$\rightarrow$ De Bruin, H. A. R. 1982. Temperature and energy balance of a water reservoir determined from standard weather data of a land station. Journal of Hydrology 59:261-274.

$\rightarrow$ Dudgeon, D., A. H. Arthington, M. O. Gessner, Z.-I. Kawabata, and D. J. Knowler. 2006. Freshwater biodiversity: importance, threats, status and conservation challenges. Biological Reviews 81:163-182.

$\rightarrow$ Eaton, J. G., J. H. McCormick, H. G. Stefan, and M. Hondzo. 1995. Extreme value analysis of a fish/temperature database. Ecological Engineering 4:289-305.

$\rightarrow$ Eaton, J. G., and R. M. Scheller. 1996. Effects of climate warming on fish thermal habitat in streams of the United States. Limnology and Oceanography 41:1109-1115.

$\rightarrow$ Elliott, J. M. 2000. Pools as refugia for brown trout during two summer droughts: trout responses to thermal and oxygen stress. Journal of Fish Biology 56:938-948.

$\rightarrow$ Elliott, J. M., and M. A. Hurley. 1997. A functional model for maximum growth of Atlantic salmon parr, Salmo salar, from two populations in northwest England. Functional Ecology 11: 592-603.

$\rightarrow$ Fang, X., and H. G. Stefan. 1999. Projections of climate change effects on water temperature characteristics of small lakes in the contiguous U.S. Climatic Change 49:377-412.

$\rightarrow$ Gillooly, J. F., J. H. Brown, G. B. West, V. M. Savage, and E. L. Charnov. 2001. Effects of size and temperature on metabolic rate. Science 293:2248-2251.

$\rightarrow$ Hamilton, S. K., S. E. Bunn, M. C. Thoms, and J. C. Marshall. 2005. Persistence of aquatic refugia between flow pulses in a dryland river system (Cooper Creek, Australia). Limnology and Oceanography 50:743-754. 
Holz, L., S. Kim, C. Petheram, G. Podger, J. Hughes, M. Kehoe, D. Aramini, S. Podger, J. Lerat, P. Poulton, J. Hornbuckle, and J.-M. Perraud. 2013. River system modelling for the Flinders and Gilbert Agricultural Resource Assessment case study analysis. A technical report to the Australian Government from the CSIRO Flinders and Gilbert Agricultural Resource Assessment, part of the North Queensland Irrigated Agriculture Strategy. CSIRO Water for a Healthy Country and Sustainable Agriculture flagships, Canberra, Australia.

$\rightarrow$ Jeffrey, S. J., J. O. Carter, K. B. Moodie, and A. R. Beswick. 2001. Using spatial interpolation to construct a comprehensive archive of Australian climate data. Environmental Modelling and Software with Environment Data News 16:309330.

$\rightarrow$ Jeong, D. I., A. Daigle, and A. St-Hilaire. 2013. Development of a stochastic water temperature model and projection of future water temperature and extreme events in the Ouelle River basin in Québec, Canada. River Research and Applications 29:805-821.

Jobling, M. 1995. Environmental biology of fishes. Chapman and Hall, London, UK.

$\rightarrow$ Kennard, M. J., B. J. Pusey, J. D. Olden, S. J. Mackay, J. L. Stein, and N. Marsh. 2010. Classification of natural flow regimes in Australia to support environmental flow management. Freshwater Biology 55:171-193.

Lerat, J., C. Egan, S. Kim, M. Gooda, A. Loy, Q. Shao, and C. Petheram. 2013. Calibration of river models for the Flinders and Gilbert catchments. A technical report to the Australian Government from the CSIRO Flinders and Gilbert Agricultural Resource Assessment, part of the North Queensland Irrigated Agriculture Strategy. CSIRO Water for a Healthy Country and Sustainable Agriculture flagships, Canberra, Australia.

$\rightarrow$ Lutterschmidt, W. I., and V. H. Hutchinson. 1997. The critical thermal maximum: data to support the onset of muscle spasm as the definitive endpoint. Canadian Journal of Zoology 75:1553-1560.

$\rightarrow$ Maltchik, L., and E. S. F. Medeiros. 2006. Conservation importance of semi-arid streams in north-eastern Brazil: implications of hydrological disturbance and species diversity. Aquatic Conservation: Marine and Freshwater Ecosystems 16:665677.

McCauley, R., and J. Casselman. 1981. The final preferendum as an index of the temperature optimum for growth in fish Proceedings of a World Symposium on Aquaculture in Heated Effluents and Recirculation Systems 2:81-93.

$\rightarrow$ McJannet, D. L., F. J. Cook, and S. Burn. 2013. Comparison of techniques for estimating evaporation from an irrigation water storage. Water Resources Research 49:1415-1428.

$\rightarrow$ McJannet, D., S. Marvanek, A. Kinsey-Henderson, C. Petheram, and J. Wallace. 2014. Persistence of in-stream waterholes in ephemeral rivers of tropical north Australia and potential impacts of climate change. Marine and Freshwater Research 65:1131-1144.

$\rightarrow$ McJannet, D. L., I. T. Webster, and F. J. Cook. 2012. An areadependent wind function for estimating open water evaporation using land-based meteorological data. Environmental Modelling and Software 31:76-83.

McJannet, D. L., I. T. Webster, M. P. Stenson, and B. S. Sherman. 2008. Estimating open water evaporation for the MurrayDarling Basin. A report to the Australian Government from the
CSIRO Murray-Darling Basin Sustainable Yields Project. CSIRO, Canberra, Australia. (Available from: doi:10.1111/J.1095 -8649.2008.01959.X)

Monteith, J. L. 1965. Evaporation and the environment. Pages 205-234 in G. E. Fogg (editor). The state and movement of water in living organisms. Cambridge University Press, London, UK.

$\rightarrow$ Newton, J. R., C. Smith-Keune, and D. R. Jerry. 2010. Thermal tolerance varies in tropical and sub-tropical populations of barramundi (Lates calcarifer) consistent with local adaptation. Aquaculture 308:S128-S132.

Pearson, R. G., and L. K. Pendridge. 1992. An ecological survey of selected rivers in Queensland with particular reference to the effects of sugar mill effluents. Report 92/02. Australian Centre for Tropical Freshwater Research, James Cook University, Townsville, Australia. (Available from: https://research .jcu.edu.au/tropwater/publications/technical-reports)

Petheram, C., D. Hughes, P. Rustomji, K. Smith, T. G. van Neil, and A. Yang. 2009. River modelling for Northern Australia. A report to the Australian Government from the CSIRO Northern Australia Sustainable Yields Project. CSIRO Water for a Healthy Country flagship, Canberra, Australia.

$\rightarrow$ Petheram, C., P. Rustomji, F. H. S. Chiew, and J. Vleeshouwer. 2012. Rainfall-runoff modelling in northern Australia: a guide to modelling strategies in the tropics. Journal of Hydrology 462/463:28-41.

Petheram, C., I. Watson, and P. Stone (editors). 2013a. Agricultural resource assessment for the Flinders catchment. A report to the Australian Government from the CSIRO Flinders and Gilbert Agricultural Resource Assessment, part of the North Queensland Irrigated Agriculture Strategy. CSIRO Water for a Healthy Country and Sustainable Agriculture flagships, Canberra, Australia.

Petheram, C., I. Watson, and P. Stone (editors). 2013b. Agricultural resource assessment for the Gilbert catchment. A report to the Australian Government from the CSIRO Flinders and Gilbert Agricultural Resource Assessment, part of the North Queensland Irrigated Agriculture Strategy. CSIRO Water for a Healthy Country and Sustainable Agriculture flagships, Canberra, Australia.

Petheram, C., and A. Yang. 2013. Climatic data and their characterisation for hydrological and agricultural scenario modelling across the Flinders and Gilbert catchments. A technical report to the Australian Government from the CSIRO Flinders and Gilbert Agricultural Resource Assessment, part of the North Queensland Irrigated Agriculture Strategy. CSIRO Water for a Healthy Country and Sustainable Agriculture flagship, Canberra, Australia.

$\rightarrow$ Pusey, B. J., and A. H. Arthington. 2003. Importance of the riparian zone to the conservation and management of freshwater fish: a review. Marine and Freshwater Research 54:116.

Pusey, B. J., M. J. Kennard, and A. H. Arthington. 2004. Freshwater fishes of north-eastern Australia. Centre for Riverine Landscapes, Griffith University. CSIRO Publishing, Collingwood, Australia.

Regier, H. A., J. A. Holmes, and D. Pauly. 1990. Influence of temperature changes on aquatic ecosystems: an interpretation of empirical data. Transactions of the American Fisheries Society 119:373-389. 
$\rightarrow$ Sheldon, F., S. E. Bunn, J. M. Hughes, A. H. Arthington, S. R. Balcombe, and C. S. Fellows. 2010. Ecological roles and threats to aquatic refugia in arid landscapes: dryland river waterholes. Marine and Freshwater Research 61:885-895.

$\rightarrow$ Sinokrot, B. A., H. G. Stefan, J. H. McCormick, and J. G. Eaton. 1995. Modeling of climate change effects on stream temperatures and fish habitats below dams and near groundwater inputs. Climatic Change 30:181-200.

$\rightarrow$ Stewart, B. A., P. G. Close, P. A. Cook, and P. M. Davies. 2013. Upper thermal tolerances of key taxonomic groups of stream invertebrates. Hydrobiologia 718:131-140. $\rightarrow$ van Vliet, M. T. H., F. Ludwig, J. J. G. Zwolsman, G. P. Weedon, and P. Kabat. 2011. Global river temperatures and sensitivity to atmospheric warming and changes in river flow. Water Resources Research 47:W02544.

Waltham, N., D. Burrows, B. Butler, J. Wallace, C. Thomas, C. James, and J. Brodie. 2013. Waterhole ecology in the Flinders and Gilbert catchments. A technical report to the Australian Government from the CSIRO Flinders and Gilbert Agricultural Resource Assessment, part of the North Queensland Irrigated Agriculture Strategy. CSIRO Water for a Healthy Country and Sustainable Agriculture flagship, Canberra, Australia. 